\title{
O turismo como indutor de desenvolvimento: revisitando as dimensões ambiental, econômica e sociocultural
}

\author{
Tourism as promoter of development: revisiting environmental, economic and \\ sociocultural layer
}

\author{
Jaciel Gustavo Kunz (KUNZ, J. G.)
}

RESUMO - O turismo constitui-se em um fenômeno social a ser evocado em meio às abordagens de desenvolvimento. Tal disposição diz respeito tanto à pesquisa científica quanto à formulação de políticas públicas integradas. Lançando mão de procedimentos metodológicos de abordagem quantitativa e qualitativa, com predominância destes, 0 presente artigo, de caráter exploratório, propõe-se, essencialmente, a elaborar uma análise do turismo como indutor de processos de desenvolvimento. O turismo sustentável, assim como o desenvolvimento que engendra, pode ser analisado a partir de aspectos das suas dimensões ambiental, econômica e sociocultural, tangenciando outros vieses, como o político-institucional. Como síntese, evidencia-se a constatação de que as benesses possíveis do turismo sustentável mostram-se como sendo de ordens das mais diversas, perpassando variadas instâncias da sociedade, prerrogativa a ser continuamente evidenciada.

Palavras-chave: Turismo; Desenvolvimento; Meio Ambiente; Sociedade; Cultura.

ABSTRACT - Tourism constitutes a social phenomenon which appears among the development approaches. Such provision is related to both scientific research and formulation of integrated public policies. Drawing on the methodological procedures of quantitative and qualitative approach, the present paper is an exploratory study, and essentially, try to elaborate an analysis of tourism as an agent of the development processes. The sustainable tourism, as well as the development that engenders, can be analyzed from their environmental, economic, social and cultural aspects, tangent other biases, such as political and institutional. As a synthesis, it is evidenced the fact that the potential virtues of sustainable tourism are shown as belonging to diverse orders, traversing several levels of the society, privilege to be continually highlighted.

Key words: Tourism; Development; Environment; Society; Culture.

\footnotetext{
* Graduação em Turismo (Bacharelado) pela Pontifícia Universidade Católica do Rio Grande do Sul (PUCRS). Mestrando em Turismo pela Universidade de Caxias do Sul (UCS). Bolsista da Coordenação de Aperfeiçoamento de Pessoal de Nível Superior (CAPES). Endereço para correspondência: Rua Francisco de Getúlio Vargas, 1130. CEP: 95070-560 - Caxias do Sul - Rio Grande do Sul (Brasil). Telefone para contato: (54) 3218-2621. Endereço eletrônico: jgkunz@ucs.br
} 


\section{INTRODUÇÃO}

Busca-se evidenciar, por meio deste artigo, interfaces possíveis entre o fenômeno turístico contemporâneo e as possibilidades de se constituir, por meio da atividade produtiva, uma alternativa de indução de desenvolvimento. Tais interfaces têm sido estabelecidas por meio de olhares e aportes teórico-metodológicos das ciências humanas e sociais, sobretudo. As variáveis envolvidas do escopo deste trabalho, articuladas nessas interfaces, também podem ser tomadas na sua dimensão de "fronteiras compartilhadas" (BARRETTO; REJOWSKI, 2001). Quais as fronteiras compartilhadas entre investigação em Turismo e demais ciências sociais, tendo em conta as possibilidades de indução do desenvolvimento?

Metodologicamente, a fim de desenvolver a problematização deste trabalho, propõe-se uma abordagem eminentemente qualitativa, recorrente em ciências sociais. A pesquisa desenvolve-se em nível predominantemente exploratório: "a pesquisa exploratória não trabalha com relação entre variáveis, mas com o levantamento da presença das variáveis e de sua caracterização quantitativa ou qualitativa" (KÖECH, 2009, p. 126). Quanto pertinente, vale-se das técnicas de revisão de literatura contemporânea e levantamento documental, privilegiando também dados estatísticos, complementando a análise qualitativa proposta. Para Köech (2009, p. 122):

\footnotetext{
A pesquisa bibliográfica é a que se desenvolve tentando explicar um problema, utilizando o conhecimento disponível a partir das teorias publicadas em livros ou obras congêneres [...] O objetivo da pesquisa bibliográfica, portanto, é o de conhecer e analisar as principais contribuições teóricas existentes sobre um determinado tema ou problema, tornando-se um instrumento indispensável para qualquer tipo de pesquisa [grifo do autor].
}

Sobre a pesquisa a partir da qual derivam as análises apresentadas neste trabalho, considera-se, ainda, que:

[...] nos voltamos para o "paradigma interpretativo", da teoria social e da pesquisa social e o seu impulso do afastamento do realismo na direção do idealismo [...] os significados subjetivos utilizados pelas pessoas na interação social são um ponto de partida para a análise [mais] objetiva da sociedade [grifo do autor]. (MAY, 2004, p. 55). 
Os procedimentos metodológicos propostos vão ao encontro do objetivo geral deste artigo, que é o de retomar a discussão sobre a prática social do turismo sustentável como possível indutora de processos de desenvolvimento. Especificamente, objetiva-se transcender a visão utilitarista a partir da qual o turismo é um setor da economia que ofereceria contribuições ao crescimento econômico nacional. Parte-se do pressuposto que o desenvolvimento, nos seus modelos mais contemporâneos é multidimensional, abarcando o meio ambiente, a economia, a sociedade e a cultura, entre outros. Tal constatação implica na premência de olhares mais aprofundados e abrangentes, que aproximem o desenvolvimento da perspectiva da mudança social, cuja consecução passa pelo planejamento integral que prime pela sustentabilidade. Essa perspectiva conduzirá as reflexões aqui propostas.

Para tal, inicialmente, é necessário apropriar-se de discussões recorrentemente instauradas, não só pelo Poder Público ou pelo setor empresarial do turismo, mas também em âmbito acadêmico, discussões estas de caráter científico, portanto.

\section{DISCUSSÕES TEÓRICAS PRELIMINARES}

Tendo em vista o fato de que as discussões teóricas sobre desenvolvimento não se exaurem facilmente, apresenta-se, para fins de elaboração deste artigo, apenas parte de seus aspectos balizadores. Nesse ínterim, busca-se abarcar a multidisciplinaridade e interdisciplinaridade presentes na discussão dos processos de desenvolvimento, esse na sua concepção mais contemporânea. O mesmo ocorre em relação ao turismo. Becker (2008, p. 82) afirma que "mesmo a dimensão econômica do processo de desenvolvimento seja, desde sempre, no contexto do sistema capitalista, a condição necessária, nunca foi condição suficiente". Nesse sentido, reforça-se que:

\footnotetext{
Atualmente o conceito de desenvolvimento está ligado a uma nova visão relacionada à qualidade de vida, sem deixar de buscar a eficiência produtiva; volta-se para as necessidades dos indivíduos, para a participação desses na [sua] região, como atuantes nesse processo de desenvolvimento (BASSAN; SIEDENBERG, 2008, p. 152).
}

Há que se atrelar essa perspectiva à propriedade endógena do desenvolvimento, ou desenvolvimento endógeno, que diz respeito à capacidade de os locais promoverem 
o desenvolvimento surgir "de dentro para fora", não se sujeitando a imposições político-econômicas "de fora para dentro". 1

Paralelamente à discussão sobre desenvolvimento contemporâneo, há que se percorrer, mesmo que minimamente, discussões sobre alguns aspectos da pesquisa em Turismo, a fim de contemplar ao objetivo específico deste artigo que é estabelecer uma discussão entre desenvolvimento e a ciência social do Turismo.

Para além de abordagens técnicas e economicistas, por vezes incorrendo em reducionismo, situam-se as complexas e numerosas variáveis do turismo, além da relação entre elas, as quais remetem a uma abordagem holística e a uma perspectiva de investigação científica em Turismo. Para Beni (2007) o objeto do Turismo vincula-se às ciências sociais.

Moesch $^{2}$ (apud Beni, 2007, p. 53), por sua vez, defende uma autonomia intelectual e um objeto do Turismo, que possuiria condições de "autojustificar-se cientificamente" a partir de um processo de teorização próprio. A referida autora busca transpor as abordagens comumente conferidas ao turismo, que são a de atividade ou setor da economia, para, ao lado da ciência social do Turismo, considerá-lo uma prática social cujos nuances possuem conteúdo humano, cultural, espacial, comunicacional e que, nesse sentido, propicia desterritorializações.

Assim, o turismo estaria passando por um "processo de cientificidade" já ocorrido em outras áreas de conhecimento, o que indica a existência de uma pequena, porém crescente comunidade de pesquisa, oriunda, majoritariamente, das ciências sociais (REJOWSKI, 1996, p. 17). O Turismo estar-se-ia constituindo em um promissor campo de estudo e de pesquisa no âmbito acadêmico (REJOWSKI, 1996).

Contudo, pontua-se que a produção acadêmica em turismo atuaria em descompasso em relação ao "fazer-saber" da área (MOESCH, 2000a, p. 11). Além disso, a diversidade de tipologias de estudos em turismo espelha a interdisciplinaridade do seu objeto, sendo que tal prerrogativa não seria condizente ao reducionismo estabelecido (MOESCH, 2000a). Para a autora, há que se combater, nesse sentido, os

\footnotetext{
${ }^{1}$ Boisier (2000) considera que: "O desenvolvimento endógeno se produz como resultado de um forte processo de articulação de atores locais e de variadas formas de capital intangível, no marco preferencial de um projeto político coletivo de desenvolvimento do território em questão [tradução nossa]" (p. 173). Ele pondera que qualquer desenvolvimento social seria, necessariamente, endógeno.

${ }^{2}$ MOESCH, M. M. Epistemologia social do turismo. 334 p. Tese (Doutorado em Ciências da Comunicação) - Escola de Comunicação e Artes, Universidade de São Paulo, São Paulo, 2004.
} 
estudos fragmentados, desarticulados, unilaterais e, em paralelo a isso, disseminar um espírito "crítico" que faça jus à autonomia intelectual na produção do saber turístico (MOESCH, 2000a, p. 12). Contudo, reconhece que até o momento "inexiste clareza epistemológica" em relação ao Turismo, isto porque se verifica como recorrente a suposição de que apenas um campo do saber é suficiente para analisar e organizar as partes constituintes do todo, o que não é desejável para que o Turismo avance como ciência (MOESCH, 2000a, p. 12). "A exemplo do que acontece em outras áreas, o desenvolvimento do conhecimento turístico ocorre condicionado ao funcionamento da sociedade contemporânea" (MOESCH, 2000a, p. 13), e isso deve ser observado.

Assim, é possível constatar que as tentativas de conceituação do turismo encontram percalços das mais diversas ordens, teóricas, metodológicas e até mesmo epistemológicas, sendo que o conceito que lhe é inerente, o de turista, parece apresentar características semelhantes, até o ponto de muitas definições conceituais de turismo apresentadas confundirem-se com a de turista ou vice-versa. Essas considerações caracterizam os reveses da pesquisa em Turismo, o qual pode ser analisado conjuntamente com possibilidades de desenvolvimento para destinos turísticos, consolidados ou em consolidação. A discussão do turismo sustentável torna-se, assim, premente:

O desenvolvimento do turismo sustentável atende às necessidades dos turistas de hoje e das regiões receptoras, ao mesmo tempo em que protege e amplia as oportunidades para o futuro e visto como um condutor ao gerenciamento de todos os recursos, de tal forma que as necessidades econômicas, sociais e estéticas possam ser satisfeitas sem desprezar a manutenção da integridade (OMT, 2003, p. 24).

O turismo sustentável, nesses termos, procura conciliar o crescimento econômico, alavancado pela sua cadeia produtiva, ao bem-estar social e à proteção ambiental, conforme será aludido posteriormente.

\section{ELEMENTOS DA DIMENSÃO AMBIENTAL DO TURISMO}

Para a OMT (2003), o turismo e o meio ambiente estariam intimamente interrelacionados. Se, por um lado, o ambiente natural e o construído constituem-se 
como bases em termos de recursos para a consolidação de atrativos e produtos (turísticos), por outro, há que se ter em conta que a atividade turística impacta tanto positiva quanto negativamente o meio ambiente. De acordo com Lemos (2000), a própria recepção demasiada de turistas levaria à depredação dos recursos naturais, gerando, além disso, um desequilíbrio ambiental, o que aponta para a problemática do “desenvolvimento auto-sustentado" (LEMOS, 2000, p. 88). Isso ocorreria porque alguns serviços que atendem ao turismo, como os de transportes, por exemplo, assentam-se no consumo de recursos não-renováveis. Moesch (2000b, p. 96), por sua vez, considera que o turismo peca por se mostrar um "evento maldimensionado" e, por vezes, "alheio aos valores ambientais locais".

Nesse sentido, tem-se paulatinamente evidenciado os impactos ambientais como mazelas da(s) atividade(s) do turismo a serem minimizadas. O extremo oposto dessa afirmação seria negligenciar a extensão dos aspectos ambientais envolvidos e os percalços que representam a magnitude de seus impactos, e não assumir, com vigor e de forma integrada, a tarefa de mitigar as repercussões negativas sobre o meio natural e maximizar, quando possível, as positivas. A sustentabilidade do turismo também pode ser perseguida inclusive por meio do saber-fazer da gestão ambiental em suas empresas ou destinos (KUNZ; DE CONTO, 2011).

Nesse contexto, vale lembrar que a qualidade ambiental ${ }^{3}$ das organizações empresas turísticas - que se instalam em destinos turísticos brasileiros mostra-se como estágio intermediário em relação à qualidade de vida dos membros da comunidade receptora.

Visando à qualidade ambiental e à melhoria do desempenho ambiental das organizações ligadas ao turismo, há que se ter claro os aspectos ambientais inerentes às atividades que elas praticam. As empresas do turismo congregam desde meios de hospedagem, passando por serviços de alimentação e até mesmo pelo transporte de passageiros. Nesse espectro de atividades, pode-se elencar como aspectos ambientais ${ }^{4}$,

\footnotetext{
3 "A qualidade ambiental consiste na utilização e na interação consciente e coerente dos elementos de natureza física, química, biológica, social, econômica, e tecnológica que busquem assegurar a sustentabilidade de um ecossistema, em que assegure conjuntamente a qualidade de vida" (VALLE, 2010, p. 38).

${ }^{4}$ Cabe, aqui, uma distinção: "Aspectos ambientais são todos os elementos das atividades, produtos ou serviços de uma organização que podem interagir com o meio ambiente". Já "impactos ambientais são
} 
por exemplo, a geração de resíduos sólidos, o lançamento de efluentes líquidos, o desperdício de recursos hídricos, entre outros. Entre os impactos ambientais que correspondem aos aspectos exemplificados, podem ser apontados: a contaminação do solo, a contaminação das águas superficiais e subterrâneas, o esgotamento de bases de recursos naturais não-renováveis, entre outros.

Esse esgotamento aponta para uma crise que é ecológica. Já a capacidade de recuperação (resiliência) dos ecossistemas diz respeito a uma crise ambiental (GUIMARÃES 5 apud RAMPAZZO, 2001).

Tanto os aspectos quanto os impactos (ambientais) podem ser dimensionados à medida que a gestão ambiental for continuamente internalizada no setor. Nesse sentido, Cooper et al. (2007) preconizam, para o turismo, as chamadas avaliações de impacto ambiental - AIAs, partindo do pressuposto de que a preservação ambiental é menos onerosa do que a correção.

Além disso, consideram-se os relatórios de impacto sobre o meio ambiente (RIMAs) como forma de monitoramento do desempenho ambiental de empresas e destinos turísticos, muitos dos quais se pautam pela oferta calcada de turismo de natureza.

Uma das preocupações mais expressivas em relação aos impactos ambientais do turismo se volta, assim, às organizações turísticas. Mas residem, também, na prática de atividades de lazer, esportes, técnico-científicas e/ou de aventura em áreas naturais protegidas, comumente denominadas unidades de conservação, como os parques nacionais, por exemplo. A afluência demasiada de turistas, que compromete a resiliência de ecossistemas locais, tem sido apontada como fator relevante. Assim, há que se encontrar indicadores ambientais e fixar, paralelamente a processos de planejamento integrado (r), a capacidade de carga turística ou capacidade de suporte de visitação. Essa fixação de capacidades de carga, que vai ao encontro das premissas do ecoturismo, não se restringe somente a unidades de conservação propriamente ditas, podendo também ser levada em consideração nas praias, por exemplo.

quaisquer modificações no meio ambiente (adversas ou benéficas) que resultem dos aspectos ambientais da organização [grifos do autor]" (MOURA, 2008, p. 103).

${ }^{5}$ GUIMARÃES, R. P. O novo padrão de desenvolvimento para o Brasil: interrelação do desenvolvimento industrial e agrícola com o meio ambiente. In: VELOSO, J. R. dos R. (Org.). A ecologia e o novo padrão de desenvolvimento no Brasil. São Paulo: Nobel, 1992, p. 19-52. 
Todas essas medidas surtem o efeito desejado à medida que incorporam a colaboração dos sujeitos visitantes, muitos dos quais, turistas. Dado o que se verifica, frequentemente, em parques turísticos, por exemplo, pode-se dizer que passa a existir um entrave, que é também comportamental: "Talvez, os turistas que levam a sério o desenvolvimento sustentável em suas vidas diárias acreditem que suas viagens anuais de férias são o único momento em que podem se comportar hedonisticamente, sem a necessidade de serem responsáveis" (SWARBROOKE, 2000, p. 15). O autor vai além, ao indagar: "Por que os turistas que buscam escapar de suas rotinas diárias deveriam se interessar por turismo sustentável?” (SWARBROOKE, 2000, p. 15). Reconhece-se, assim, que a educação ambiental torna-se uma das principais ferramentas do turismo sustentável (NEIMAN; RABINOVICI, 2010) que se deseja. Pode-se considerar, ainda, que modelos "alternativos", de turismo, por meio de seus profissionais, constituem-se como ferramentas de educação ambiental e, assim, de desenvolvimento sustentável para os destinos turísticos.

De fato, o turismo pode degradar os recursos naturais. Por outro lado, a visitação turística pode (re) valorizar o patrimônio natural de muitas localidades, viabilizando a preservação ambiental em longo prazo. Reitera-se, assim, que: “O desenvolvimento não se mantém se a base de recursos ambientais se deteriora; o meio ambiente não pode ser protegido se o crescimento não leva em conta as conseqüências da destruição ambiental" (RAMPAZZO, 2001, p. 172). E as políticas turísticas devem incorporar essa perspectiva.

Em suma, no contexto do turismo, há que se avaliar, de forma contínua, os custos ambientais no desenvolvimento de suas atividades em relação aos benefícios de ordem econômico-financeiros que proporciona. Somente dessa forma o turismo ocorrerá de forma responsável e sustentável, efetivando sua colaboração ao desenvolvimento.

\section{ASPECTOS DA DIMENSÃO ECONÔMICA DO TURISMO}

O turismo tem sido apontado, desde há muito anos, porém com um vigor cada vez maior, como um setor da economia dos mais promissores, tanto pela extensão da

\footnotetext{
${ }^{6}$ Em oposição aos modelos de turismo que se desenvolvem de forma massiva, não respeitando os limites do ambiente natural.
} 
sua cadeia produtiva, quanto pelo efeito multiplicador que desencadeia, configurando, assim, importantes oportunidades de mercado e alternativa de desenvolvimento econômico. As repercussões positivas da dimensão econômica do Turismo na economia têm sido perseguidas por gestores públicos e privados e ocupado investigadores de várias universidades e centros de pesquisas no desenvolvimento de estudos a esse respeito. Isso se deve, entre outros fatores, à difícil mensuração dos impactos econômicos do turismo, não raro incorrendo e sub ou superestimação desses impactos.

A comunidade receptora pode ser beneficiada pelo turismo ao ter suas empresas e negócios integrados à cadeia produtiva do turismo, o que promove um evidente crescimento econômico (BENI, 2006).

Em nível de Brasil, "a atividade transporte é a que mais contribui para o total de ocupados no setor [grifo do autor]" (IPEA, 2010, p. 333). É a atividade que mais contribui com empregos formais, no universo das atividades características do turismo (ACTs) no Brasil (IPEA, 2010). Em paralelo, têm sido evidenciados, de forma recorrente, dados que apontam para um incremento do movimento de passageiros que se utilizam do transporte aéreo no país. Há se considerar esse cenário, em todos os seus desdobramentos econômicos ${ }^{7}$.

Para o Sistema Integrado de Informações sobre Mercado de Trabalho no Setor de Turismo (SIMT), estruturado pelo Instituto de Pesquisas Econômicas Aplicadas (IPEA) em parceria com o Ministério do Turismo, fixou-se como seis as ACTs a serem consideradas, quais sejam: alojamento, agências de viagens, transportes, aluguel de transportes, auxiliar de transportes, alimentação e cultura e lazer (IPEA, 2010).

Há que se atentar para o fato de que, nessas atividades, o que notadamente prepondera é a oferta e o consumo turístico de serviços, reconhecidamente um setor com significativa capacidade de empregabilidade e de dinamização da base econômica local, regional e nacional.

Tal constatação corrobora com um dos "sete mitos do turismo" explicitados por Lemos (2000, p. 77). Os mitos a que o autor se refere dizem respeito a interpretações equivocadas sobre o turismo, que mesmo que amplamente disseminadas, não

\footnotetext{
${ }^{7}$ Dados divulgados no mês de julho de 2011 dão conta de um aumento de $17,8 \%$ no mercado doméstico de passageiros que utilizam o modal aéreo em relação ao mesmo período do ano passado no Brasil. Foi a segunda maior taxa de incremento em nível mundial. Revela-se, como contraponto, a estagnação do setor de transporte aéreo de cargas, também em nível de mundo (IATA, 2011).
} 
corresponderiam à realidade do setor. Dentre eles, figuraria o mito do turismo como indústria. Este último "mito" reafirma a proposição na qual o turismo é atrelado à economia de serviços. Para Lemos (2000), considerando o fato de a oferta turística estar baseada no setor de serviços, entre outros fatores, a abordagem do turismo como indústria não procede.

A fim de se oferecer um panorama do turismo no Brasil, apresenta-se a taxa de crescimento anual de ocupações formais e informais em ACTs, que foi, no período compreendido entre 2002 e 2008, de 3,6\%, contra 2,6\% do da economia brasileira como um todo (IPEA, 2010). Segundo levantamento realizado, em dezembro de 2008, a fim de compor o SIMT do IPEA, o número de pessoas empregadas em ACTs ultrapassava a marca dos dois milhões, o que representava um aumento de $24 \%$ em relação ao levantamento realizado em 2002. Contudo, de acordo com a mesma fonte, mais da metade do contingente de 2008 tinha vínculo empregatício informal. Ainda, tem-se uma disparidade regional da distribuição proporcional e absoluta de postos de trabalho em ACTs, formais ou informais o que deve ser atenuado, para que a sustentabilidade se instaure (IPEA, 2010). A sazonalidade que acomete boa parte dos destinos turísticos brasileiros pode ser fator interveniente nos padrões de empregabilidade da área.

Porém, mais do que discutir a contribuição do turismo no crescimento econômico das regiões brasileiras, é necessário, também, aludir ao "dinamismo do setor" e a contribuição aos processos de desenvolvimento regional (IPEA, 2010, p. 341). Esses fatores repercutem também na dimensão sociocultural do turismo sustentável.

\section{ASPECTOS DA DIMENSÃO SOCIOCULTURAL DO TURISMO}

Conforme aludido anteriormente, é possível evidenciar o turismo como fenômeno complexo, manifesto, sobretudo, no campo sociocultural das práticas humanas, pautado pela mobilidade, no tempo e no espaço. Tempo e espaço figurariam entre as categorias fundantes desse fenômeno, que para Moesch (2000b, p. 97) é “estimulador dos sonhos". O turismo pode ser situado no contexto dos nomadismos contemporâneos (GASTAL, 2005). 
No campo social, o turismo atua fortemente, impactando tanto de forma positiva quanto negativamente. A título de exemplificação pode-se considerar que, se, por um lado, o turismo pode gerar o êxodo rural, ele pode também impedir a emigração (MOESCH, 2000b). Beni (2006) também cita como impactos do turismo na população local: oportunidades de emprego e de negócios, maior autoestima da comunidade receptora, entre outros.

Apresenta-se um dos componentes da dimensão sociocultural do turismo: a mobilidade humana, que teria conferido ao mundo uma nova característica, sendo um dos sinais mais característicos da contemporaneidade. Junto a esse contexto figuraria o fenômeno turístico, como fator socioeconômico importantíssimo que intensifica e aperfeiçoa a mobilidade humana (BENI, 2007). A globalização possui como componente a intensificação dos fluxos, tanto de informações, de cargas ou de pessoas. Logo, o turismo, ao mesmo tempo em que pode se tornar parte indissociável da globalização, é diretamente influenciado por seus ditames.

\begin{abstract}
A necessidade de se locomover de um espaço a outro sempre esteve presente na história do homem e, nos últimos tempos, ganhou importância crescente e contornos específicos. Vivemos numa sociedade globalizada, de alta tecnologia, repleta de motivações para viajar [...] (VALENTE e CURY, 2004, p. 45).
\end{abstract}

Entretanto, pondera-se que:

O processo de globalização tem sido apresentado como fenômeno contemporâneo, nele destacando-se, além das já conhecidas questões econômicas e políticas, a ampliação dos deslocamentos humanos ao redor do planeta, não só por razões turísticas (GASTAL, 2005, p. 51).

O momento histórico a que se faz referência experimenta, entre outros aspectos, intensa urbanização. Como desdobramento, aponta-se a exiguidade de espaços públicos, por exemplo. Por outro lado, e como paradoxo, o turismo urbano configura-se como possibilidade de experiências qualificadas em termos de novos estranhamentos ${ }^{8}$, onde se assenta o turismo contemporâneo.

Redimensionando o significado social do turismo, e do próprio turismo, Gastal e

\footnotetext{
${ }^{8} \mathrm{O}$ turista, em seus deslocamentos, ao se defrontar com o novo e o inesperado, vivenciaria processos de mobilização subjetiva que o levariam a parar e a re-olhar, a repensar, reavaliar, a ressignificar não só a situação, o ambiente, as práticas vivenciadas naquele momento e naquele lugar, mas muitas das suas experiências passadas (GASTAL; MOESCH, 2007, p. 11).
} 
Moesch (2007, p. 60) propõem uma nova categoria de turista a ser considerada: o "turista-cidadão" ou "cidadão-turista". As pessoas (cidadãos) compõem os fluxos que percorrem o espaço urbano que habitam. Dentro do contexto dos nomadismos, essas pessoas são convidadas a se movimentarem transcendendo suas práticas cotidianas, dentro dos limites das suas próprias cidades. Isso implica transformar essas pessoas em turistas, que podem, por meio dos seus deslocamentos, apropriarem-se de espaços e situações, num efetivo exercício de cidadania (GASTAL; MOESCH, 2007).

Outro elemento continuamente defendido é o "turismo social", modalidade essa, que na sua abordagem mais clássica, "trata das viagens de lazer para segmentos populares e para grupos em situação de vulnerabilidade" (BRASIL, 2008, p. 6), o que deve ser estimulado de forma transversal a todos os segmentos de turismo. Nesse sentido, o Ministério do Turismo tem em sua concepção que o brasileiro deve ser o principal beneficiado pelo desenvolvimento do turismo no país, e, em sua "viagem de inclusão", procura evidenciar a consecução dos objetivos sociais (como, por exemplo, a inserção social da população), como foco do modelo de desenvolvimento proposto, sendo o turismo um potencial meio para isso (BRASIL, 2004). Vale lembrar que a inclusão também se estabelece na medida em que a visitação turística a determinados locais é pautada por ampla acessibilidade para portadores das múltiplas necessidades especiais.

O órgão federal em questão também tem preconizado como alternativa ao turismo massivo, a complementação da oferta turística por produtos do turismo de base comunitária (TBC):

\footnotetext{
O turismo de base comunitária, portanto, tende a ser aquele tipo de turismo que, em tese, favorece a coesão e o laço social e o sentido coletivo de vida em sociedade, e que por esta via, promove a qualidade de vida, o sentido de inclusão, a valorização da cultura local e o sentimento de pertencimento [...] representa, portanto, a interpretação "local" do turismo, frente às projeções de demandas e de cenários do grupo social do destino, tendo como pano de fundo a dinâmica do mundo globalizado, mas não as imposições da globalização [grifo do autor] (PIMENTEL, 2010, p. 239).
}

Assim, o turismo encontra, no campo da cultura, numerosas possibilidades de ampliação de seus fluxos. Isso ocorre por meio dos atrativos turísticos categorizados como culturais, em geral representativos do patrimônio material e imaterial pertencente

\footnotetext{
${ }^{9}$ Refere-se ao título do Plano Nacional de Turismo 2007-2010.
} 
a comunidades receptoras. Tal patrimônio pauta-se pela memória e pelo imaginário social historicamente constituído e, ao mesmo tempo, em constituição. Retextualizamse, assim, as identidades culturais dos locais, que passam a compor a oferta cultural de destinos turísticos. Para além da formação de um segmento do mercado turístico, podese considerar o turismo cultural ${ }^{10}$ como uma das motivações de viagem das mais destacadas.

Por um lado, o turismo tem sido apontado por impactos negativos, como, exemplo, determinados esteriótipos e a homogeneização de culturas tradicionais e locais. Por outro, a possibilidade de resgate, preservação e ressignificação do patrimônio cultural tem reafirmado o turismo nos seus benefícios. Nesses termos, o turismo possui como virtude a "propagação das culturas" (MOESCH, 2000b, p. 99). Nesse contexto, reconhece-se que o componente social da política de turismo pode incentivar a criatividade, as artes e as manifestações sociais, artesanais e/ou folclóricas (BENI, 2007).

Pimentel (2010, p. 239) oferece contribuições a uma necessária abordagem humana e sociocultural do turismo:

O turismo realizado do ponto de vista cultural é realizado na escala humana e significa aprendizagem, encontro de pessoas. Funciona como estimulante da vitalidade, como fator educativo, como realização do direito ao lazer e como crescimento pessoal.

O lazer e a hospitalidade turística - essa transposta da oferta de hospedagem para atuar como processo social, de trocas simbólicas e de reciprocidade entre sujeitos também figuram como um dos aspectos da dimensão sociocultural do turismo a serem considerados em termos de desenvolvimento, sobretudo nos modelos que privilegiam como finalidades o empoderamento humano, o bem-estar social e a qualidade de vida das comunidades receptoras.

Turismo é diálogo entre culturas diversas, e a riqueza das culturas está em suas especificidades, nas diferenças. Afinal, se através do turismo se pode descobrir a diversidade e exercitar a capacidade de conviver com a diferença, se podemos exercer a comunicação, a negociação e o compromisso mútuo, enfim, estreitar os laços sociais e pessoais e aproximar os homens, estruturas que facilitem esses encontros devem ser estimuladas e perpetuadas (PIMENTEL, 2010, p. 239).

\footnotetext{
${ }^{10} \mathrm{Na}$ concepção de um grande número de pesquisadores, consensua-se que toda modalidade de turismo é, necessariamente, cultural.
} 
Dada essas possibilidades, infere-se que o turismo pode potencializar os laços sociais e o patrimônio cultural das comunidades receptoras, delas com os turistas e, dessa forma, amplia as possibilidades de coesão social, com vistas ao desenvolvimento. A condução de políticas turísticas de nível local, que tenham como eixo condutor a sustentabilidade, pressupõe a mobilização do capital social dos atores do desenvolvimento.

Sob outra perspectiva, o turismo sustentável (por meio do seu "imperativo" participativo) pode ser um indutor da acumulação de capital social e, assim, um possibilitador de novas experiências de desenvolvimento, esse entendido de uma forma mais ampla. Considera-se, assim, que os cenários político-institucionais da sustentabilidade também compõem a discussão do turismo como alternativa de indução do desenvolvimento.

\section{O TURISMO COMO INDUTOR DE DESENVOLVIMENTO}

O turismo sustentável possui como foco, primordialmente, as populações locais e regionais receptoras de turistas. Essas escalas são elementares para a compreensão de modelos alternativos de desenvolvimento, que sejam menos setoriais e mais integrais, integrados e integradores. Demarca-se que o desenvolvimento tem na endogenia e na sustentabilidade propriedades inerentes. As escalas comumente utilizadas têm transitado, sobretudo, entre o local e o regional, por vezes tênues entre si.

O turismo inclui-se entre os setores entendidos como motrizes do desenvolvimento para determinadas regiões. Dito de outra forma, o turismo - planejado e sustentável - reconhecidamente possui um grande potencial de promovê-lo. Isso se deve, sobretudo, ao fato de o turismo sustentável gerar fluxo de divisas entre uma região teoricamente mais rica, para outra, em tese, desfavorecida (BENI, 2004). O resultado é um maior equilíbrio intra e interregional, levando renda, infraestrutura, justiça social e qualidade de vida a populações que habitam regiões mais periféricas. $\mathrm{O}$ turismo seria capaz de "diluir divisores físicos" e "limites políticos" e tem cumprido, além disso, o papel de "alavanca simbólica" de desenvolvimento integrado, atuando, também, como “balizador da integração regional” (MOESCH, 2000b, p. 100). 
Assinala-se que:

Em regiões de economia estagnada ou em franco retrocesso é possível que o funcionamento adequado de algum centro turístico contribua para melhorar a receita, se não dos habitantes de toda a região, pelo menos dos que vivem nesses lugares. E nas regiões com economias em crescimento os municípios turísticos podem somar-se para acelerar esse processo (BOULLÓN, 2005, p. 76).

Essa proposição é corroborada pelo caso brasileiro, no qual "o setor de turismo tem sido apontado como importante alternativa de criação de oportunidades de trabalho em projetos de desenvolvimento sustentável, seja no âmbito nacional ou local" (IPEA, 2010, p. 327). Do mesmo modo, de acordo com Moesch (2006), o turismo possui uma grande capacidade de atuar favoravelmente nessa direção, seja pela dinamização da economia ou pela geração de bem-estar social, por trabalhar com a autoestima da comunidade receptora. Assim, a gama de contribuições do setor do turismo para o desenvolvimento vai desde o encorajamento da comunidade para a cooperação, até aspectos mais visíveis, como melhoria dos níveis de renda de parcelas da população.

O passo decisivo em termos de uma alavanca para um possível processo de desenvolvimento encontra-se associado à capacidade de organização social dos territórios, isto é, à capacidade que determinada sociedade possui para transformar impulsos de crescimento em estados mais complexos de desenvolvimento (ALVES, 2010).

Assim, o turismo constitui-se não só como um elemento de planejamento regional setorial. Dada a condição de protagonista do desenvolvimento em algumas regiões em especial, e como coadjuvante em outras, o turismo atua - ou deve atuar como fator a ser considerado no planejamento macro e de ordenamento territorial, com vistas ao desenvolvimento sustentável.

Nesse ínterim, do qual desponta a premência por participação ativa (e não reativa) das comunidades receptoras, retoma-se a discussão da sua sensibilização, essa como requisito para o turismo atuar como vetor de desenvolvimento regional sustentável, em todas as suas macrodimensões. Tal temática torna-se relevante na medida em que há um imperativo da participação da comunidade local nos processos de desenvolvimento do turismo sustentável, a ponto de considerá-la protagonista. 
Embora se identifiquem, nas últimas décadas, iniciativas no sentido de "conscientizar" a comunidade receptora para "bem receber" o turista, essa disposição não abarca a totalidade de medidas/ações que deveriam envolver os processos de desenvolvimento pelo turismo sustentável, dentre as quais é possível citar a sensibilização de comunidades receptoras, sobretudo em nível local. A sensibilização das comunidades receptoras de turistas cria condições para a participação e mobilização social. Assim, são possibilitados, paulatinamente, o empoderamento e autonomia dos atores sociais do turismo. Esses processos podem converter-se em benesses para o desenvolvimento, extrapolando a esfera setorial do turismo como atividade produtiva.

As benesses inerentes ao desenvolvimento, que tendem a emergir intensificação dos fluxos turísticos, só serão plenas em seus atributos, à medida que se observar e se agir estrategicamente em relação aos aspectos e impactos ambientais daí decorrentes, pois atuam como fatores intervenientes na(s) atividade(s) turística(s). Pondera-se, pois, que se forem planejados adequadamente, o turismo, o desenvolvimento econômico e a preservação ambiental podem coexistir de forma (mais) harmoniosa. Não se pode olvidar os custos sociais do turismo, a serem mitigados. O saneamento básico é um das precondições para que o turismo sustentável consolide-se como fator de desenvolvimento, colaborando para um progresso não só material, mas também no sentido de qualificar as comunidades receptoras, promovendo um desenvolvimento integrado. Não se pode prescindir da observância dos preceitos da sustentabilidade. Essa sustentabilidade configura-se como multidimensional, assim como o é o turismo, esse tomado tanto na condição de fenômeno espacial quanto na condição na de fenômeno sociocultural, e não somente na condição de cadeia produtiva, o que seria insuficiente.

\section{ENCAMINHAMENTOS FINAIS}

Transpor a abordagem do Turismo, conferida por ciências sociais, para a discussão da problemática dos processos de desenvolvimento contemporâneo, por vezes desequilibrados, tem se mostrado como um desafio, cujo enfrentamento torna-se, pois, necessário. O fenômeno turístico por si só exige um aporte multidisciplinar. Quando relacionado à problemática do desenvolvimento de um país, essa exigência é 
reafirmada, redimensionada e complexificada. Logo, preconizar o turismo sustentável como indutor do desenvolvimento (sustentável) é mencionar numerosos impactos positivos, nas áreas ambiental, econômica, sociocultural, primando por uma transversalidade desses vieses - que se situam, primordialmente, no campo social quanto em termos teóricos quanto em termos de planejamento e políticas públicas.

É latente que se ressalte, em paralelo, que o turismo só será plenamente desejável, no que tange à sustentabilidade e ao desenvolvimento, à medida que se observarem princípios de proteção e até mesmo de conservação ambiental, em alguns casos. Priorizam-se, assim, modelos de turismo que o concebem como atividade que ocorre em harmonia com o ambiente no qual está circunscrito.

Há que se potencializar os negócios atrelados ao turismo como oportunidades de mercado, além de transpor essa concepção para o turismo como indutor do desenvolvimento, integralmente em suas macrodimensões, e, dessa forma, primar pela sustentabilidade dos processos envolvidos. O turismo será, de fato, um vetor de desenvolvimento à medida que se deslocar do atual foco no turista, foco esse pertencente a um ideário mercadológico, com a finalidade de abarcar, também, os anseios das comunidades receptoras de turistas. Dessa forma, o turismo poderá tornarse, de forma mais efetiva, um indutor de desenvolvimento.

\section{REFERÊNCIAS}

ALVES, J. A. B. Arranjo produtivo local e desenvolvimento regional: uma reflexão do APL de Turismo Rota da Amizade (SC, Brasil). In: Turismo e Sociedade, Curitiba, v. 3, n. 1 , abr. 2010, p. 8-36.

BARRETTO, M; REJOWSKI, M. Introdução. In: (Org.). Turismo: interfaces, desafios e incertezas. Caxias do Sul: EDUCS, 2001.

BASSAN, D. S.; SIEDENBERG, D. R. Desenvolvimento buscando a redução das desigualdades. In: BECKER, D. F; WITTMANN, M. L. (Org.). Desenvolvimento regional: abordagens multidisciplinares. 2. ed. Santa Cruz do Sul: EDUNISC, 2008, p. 137-156.

BECKER, D. F. A contradição em processo: o local e o global na dinâmica do desenvolvimento regional. In: ; WITTMANN, M. L. (Org.). Desenvolvimento regional: abordagens multidisciplinares. 2. ed. Santa Cruz do Sul: EDUNISC, 2008, p. 67-116. 
BENI, M. C. Análise estrutural do turismo. 12. ed. São Paulo: Senac, 2007.

Política e planejamento de turismo no Brasil. São Paulo: Aleph, 2006.

Um outro turismo é possível? A recriação de uma nova ética. In: GASTAL, S.; MOESCH, M. (Org.). Um outro turismo é possível. São Paulo: Contexto, 2004, p. 1124.

BOISIER, S. Desarollo (local): ¿De qué estamos hablando? In: BECKER, D. F.; BANDEIRA, P. S. (Org.). Desenvolvimento local-regional: determinantes e desafios contemporâneos, v. 1. Santa Cruz do Sul: EDUNISC, 2000, p. 151-186.

BOULLÓN, R. C. Os municípios turísticos. Bauru: EDUSC, 2005.

BRASIL. Ministério do Turismo. Turismo Social - diálogos do Turismo: uma viagem de inclusão. Rio de Janeiro: IBAM, 2008.

Ministério do Turismo. Plano Nacional de Turismo 2007-2010. Brasília: Ministério do Turismo, 2007.

Ministério do Turismo. Programa de Regionalização do Turismo: Roteiros do Brasil: Diretrizes Operacionais. Brasília: Ministério do Turismo, 2004. Disponível em: <http://www.gestour.com.br/salao_turismo/diretrizes_operacionais.pdf>. Acesso em: 19/04/2011.

COOPER, C.; FLETCHER, J.; FYALL, A.; GILBERT, D.; WANHILL, S. Turismo: princípios e prática. 3. ed. Porto Alegre: Bookman, 2007.

GASTAL, S. Nomadismo e Turismo: viagem como vida no espaço. In: TRIGO, L. G. G. (Org.). Análises regionais e globais do turismo brasileiro. São Paulo: Roca, 2005, p. 49-58.

2007.

; MOESCH, M. Turismo, políticas públicas e cidadania. São Paulo: Aleph,

IATA. International Air Transportation Association. Passenger... In: Press Releases, n. 41, 01 set. 2011. Disponível em: <http://www.iata.org/pressroom/pr/Pages/2011-09-0101.aspx >. Acesso em: 11/09/2011.

IPEA. Instituto de Pesquisa Econômica Aplicada. Brasil em desenvolvimento: Estado, Planejamento e Políticas Públicas, vol. 2. Brasília: IPEA, 2010.

KÖECH, J. C. Fundamentos de metodologia científica: teoria da ciência e técnicas de pesquisa. 28. ed. Petrópolis: Vozes, 2009. 
KUNZ, J. G.; DE CONTO, S. M. O turismo brasileiro e a relevância da gestão ambiental em terminais aeroportuários. In: VII SEMINÁRIO DA ASSOCIAÇÃO NACIONAL DE PESQUISA E PÓS-GRADUAÇÃO EM TURISMO, 8., Balneário Camboriú, 2011. Anais... São Paulo: Aleph, 2011.

LEMOS, L. de. Os sete mitos do Turismo: a busca de alguns conceitos fundamentais. In: GASTAL, S. (Org.). Turismo: nove propostas para um saber-fazer. 2. ed. Porto Alegre: EDIPUCRS, 2000.

MAY, T. Pesquisa social: questões, métodos e processos. 3. ed. Porto Alegre: Artmed, 2004.

MOESCH, M. Documento-referência da I Conferência Municipal de Turismo de Viamão. Viamão: Prefeitura Municipal, 2006.

O fazer-saber turístico: limites e possibilidades de superação. In: GASTAL, S. (Org.). Turismo: nove propostas para um saber-fazer. 2. ed. Porto Alegre: EDIPUCRS, 2000a, p. 11-28.

MOESCH, N. Turismo: virtudes e pecados. In: GASTAL, S. (Org.). Turismo: nove propostas para um saber-fazer. 2. ed. Porto Alegre: EDIPUCRS, 2000b, p. 93-102.

MOURA, L. Qualidade e gestão ambiental: sustentabilidade e implantação da ISO 14.001. 5. ed. São Paulo: Juarez de Oliveira, 2008.

NEIMAN, Z.; RABINOVICI, A. (Org.). Turismo e meio ambiente no Brasil. Barueri: Manole, 2010.

OMT. Organização Mundial do Turismo. Guia de Desenvolvimento do Turismo Sustentável. Trad. Sandra Netz. Porto Alegre: Bookman, 2003.

PIMENTEL, A. B. Dádiva e hospitalidade no sistema de hospedagem domiciliar. In: BARTHOLO, R; BURSZTYN, I.; SANSOLO, D. G. (Org.). Turismo de Base Comunitária: diversidade de olhares e experiências brasileiras. Rio de Janeiro: Letra e Imagem, 2010, p. 216-239.

REJOWSKI, M. Turismo e pesquisa científica. 7. ed. Campinas: Papirus, 1996.

RAMPAZZO, S. E. A questão ambiental no contexto do desenvolvimento econômico. In: BECKER, D. F. (Org.). Desenvolvimento sustentável: necessidade e/ou possibilidade? Santa Cruz do Sul: EDUNISC, 2011, p. 157-188.

SWARBROOKE, J. Turismo sustentável. Vol. 1. São Paulo: Aleph, 2000. 
VALENTE, F. J.; CURY, R. M. Transporte aéreo e a Integração Logística com as Atividades Turísticas. In: Turismo: Visão e Ação, Balneário Camboriú, v. 6, n. 1, abr.jun., 2004, p. 27-45.

VALLE, C. E. do. Qualidade Ambiental: ISO 14001. 10. ed. São Paulo: Senac, 2010.

Recebido em: 20-12-2011.

Aprovado em: 20-01-2012. 